\title{
Variabilidade genética e coeficiente de determinação em genótipos de algodoeiro quanto a qualidade da fibra
}

\section{Genetic variability and coefficient of determination in cotton genotypes as the quality of the fiber}

\author{
Daniel Oliveira Cardoso Bonifácio ${ }^{1}$, Fernanda de Melo Mundim ${ }^{2}$, Larissa Barbosa de Sousa ${ }^{3}$
}

Resumo: O algodão é a mais importante fibra têxtil do mundo e a sua qualidade é o que garante o retorno investido pelo produtor. O trabalho teve como objetivo avaliar a variabilidade genética entre 22 genótipos de algodoeiro de fibra branca do Programa de Melhoramento Genético do Algodoeiro, da Universidade Federal de Uberlândia, quanto a qualidade da fibra e determinar o coeficiente de determinação genotípico dos caracteres. O experimento foi realizado na fazenda Capim Branco, em Uberlândia-MG, na safra 2012/2013. O delineamento experimental foi de blocos casualizados com três repetições. Avaliou-se 20 genótipos de algodoeiro. Com o auxílio do aparelho High Volume Instrument, determinou-se o índice de consistência a fiação, índice micronaire, maturidade da fibra, comprimento da fibra, uniformidade de comprimento, índice de fibras curtas, resistência, alongamento, reflectância e grau de amarelecimento. As linhagens do Programa de Melhoramento genético do Algodoeiro da Universidade Federal de Uberlândia, com exceção da UFUJP13-17 e UFUJP13-20, atendem as exigências da indústria têxtil e apresentam variabilidade suficiente para seguir no processo de melhoramento. A variação entre os genótipos foi em maior parte de natureza genética, com coeficiente de determinação acima de $80 \%$.

Palavras-chaves: Gossypium hirsutum, características intrínsecas da fibra, melhoramento genético.

\begin{abstract}
Cotton is the most important textile fiber in the world and its quality is what ensures the return invested by the producer. The objective of this work was to evaluate the genetic variability among 22 genotypes of cotton fiber white of the Program of Genetic Improvement of Cotton, from the Federal University of Uberlandia, as fiber quality and determine the coefficient of determination of genotypic characters. The experiment was carried out on the farm Capim Branco, in Uberlandia, MG, in season 2012/2013. The experimental design was a randomized complete block with three replications. Evaluated 20 cotton genotypes. With the aid of the appliance High Volume Instrument, it was determined that the index of consistency the wiring, index micronaire, fiber maturity, fiber length, length uniformity index of short fibers, strength, elongation, reflectance and degree of yellowing. The lines of the Program of genetic improvement of cotton from the Federal University of Uberlandia, with the exception of UFUJP13-17 and UFUJP13-20, meet the requirements of the textile industry and feature variability sufficient to follow in the process of improvement. The variation between the genotypes was in most of nature genetics, with coefficient of determination above $80 \%$.
\end{abstract}

Palavras-chaves: Gossypium hirsutum, intrinsic characteristics of fiber, genetic improvement.

\footnotetext{
*Autor para correspondência

Recebido para publicação em 29/08/2015; aprovado em 15/09/2015

${ }^{1}$ Universidade Federal de Uberlândia-UFU. E-mail: danieludia13@ @otmail.com

${ }^{2}$ Universidade Federal de Uberlândia-UFU, E-mail: ff_mundim@ @otmail.com

${ }^{3}$ Universidade Federal de Uberlândia-UFU, E-mail: larissa@iciag.ufu.br
} 


\section{INTRODUÇÃO}

O algodoeiro (Gossypium hirsutum L.) é uma espécie do gênero Gossypium, da família Malvaceae, sendo responsável por um grande interesse sócio econômico em todo o mundo, devido ao fato de ser responsável pela movimentação de setores da sociedade, como indústria têxtil (CHITARRA, 2014), que é considerada uma das maiores.

O algodão é utilizado pelo homem desde tempos remotos. Sua domesticação ocorreu há mais de 4.000 anos no sul da Arábia (BELTRÃO, 2004) e sua importância cresceu com o passar dos tempos e civilizações.

Hoje o algodoeiro é cultivado por mais de 60 países, nos cinco continentes, onde a Índia, China, Estados Unidos, Paquistão e Brasil são os principais produtores da fibra, sendo responsável por quase metade da vestidura da população mundial (ICAC, 2015). O valor econômico da cultura aumenta com a produção de biodiesel, alimentação de animais e humana, produtos farmacêuticos, fitoterápicos, óleos, etc. (ABRAPA, 2014).

No mercado têxtil, o Brasil ocupa a sexta posição a nível mundial, consumindo anualmente um milhão $\mathrm{kg} \mathrm{ha}^{-1} \mathrm{de}$ pluma de algodão (ABRAPA, 2014). A indústria procura fibras finas, resistentes e uniformes, para que possa suprir sua necessidade e não prejudicar o processo de fiação (FREIRE et al., 1997).

A alta qualidade tecnológica da fibra é fator primordial para que o algodão tenha uma boa aceitação no mercado externo. Com isso, as avaliações da qualidade, estão cada vez mais rigorosas e são executadas por laboratórios, que a cada dia apresentam maior qualificação.

A fibra do algodão é uma única célula, que cresce e se desenvolve por aproximadamente 50-60 dias, período em que ocorre a elongação e deposição de celulose para formação da mesma (BELTRÃO, 2006).

A comercialização da fibra de algodão leva em consideração suas características intrínsecas e extrínsecas, classificadas atualmente pelo sistema HVI (High Volume Instrument), atendendo a legislação vigente, o que possibilita menor subjetividade da classificação manual/visual, além de oferecer outras determinações adicionais importantes para a classificação, que refletem na qualidade (VIDAL NETO; FREIRE, 2009).

Devido à expressiva participação econômica e a exigência do mercado externo quanto a qualidade da fibra, cotonicultores estão cada vez mais atentos a atendê-las. A constante necessidade na melhoria das características da pluma produzida, sem que a produtividade seja afetada, tem sido uma das principais exigências. Logo não adianta uma genética de qualidade, se o ambiente não for favorável para a sua expressão. Diante disso, é de extrema importância o conhecimento dos fatores que interferem na qualidade da fibra.

O melhoramento do algodoeiro, é um forte aliado na obtenção de plantas que além de adaptadas a região, apresentem alto rendimento (PEDROSA, 2011), e tem como objetivos principais, atender o aumento da produtividade, de porte, maturação uniforme e resistência às principais pragas e doenças (PENNA, 2005), bem como a obtenção de fibras de qualidade.

Conforme Penna (1982) e Resende (2014), as características tecnológicas da fibra mais importantes são, o comprimento da fibra, resistência, maturidade da fibra e índice micronaire.

O trabalho teve como objetivo avaliar a variabilidade genética entre 22 genótipos de algodoeiro de fibra branca do Programa de Melhoramento Genético do Algodoeiro (PROMALG) da Universidade Federal de Uberlândia (UFU) quanto a qualidade da fibra e determinar o coeficiente de determinação genotípico $\left(\mathrm{h}^{2}\right)$ dos caracteres.

\section{MATERIAL E MÉTODOS}

$\mathrm{O}$ experimento foi conduzido em uma área experimental localizada na Fazenda Capim Branco (18 $52^{\circ}$ 'S; 48 $20^{\prime} \mathrm{W}$ e $805 \mathrm{~m}$ de altitude), pertencente à Universidade Federal de Uberlândia, no município de Uberlândia, Minas Gerais, na safra 2012/2013.

Segundo os dados climáticos (1981 a 2008) fornecidos pelo Instituto de Geografia da UFU, Uberlândia apresenta temperatura média do ar de $22,4^{\circ} \mathrm{C}$, umidade relativa do ar média de $70 \%$ e precipitação pluvial anual média de 1.584 $\mathrm{mm}$ por ano.

A área em que foi realizado o experimento situa-se sobre Latossolo Vermelho escuro, de textura argilosa. Antes da implantação do experimento, coletou-se uma amostra composta de solo e realizou as análises química e física para fins de recomendação de calagem e adubação.

O preparo do solo foi executado de forma convencional, com uma aração e duas gradagens. Antes da semeadura, a área foi sulcada e adubada, conforme análise do solo.

Foram avaliados 20 genótipos de algodoeiro provenientes de cruzamentos biparentais, do Programa de Melhoramento genético de plantas da Universidade Federal de Uberlândia (UFUJP13-01, UFUJP13-02, UFUJP13-03, UFUJP13-04, UFUJP13-05, UFUJP13-06, UFUJP13-07, UFUJP13-08, UFUJP13-09, UFUJP13-10, UFUJP13-11, UFUJP13-12, UFUJP13-13, UFUJP13-14, UFUJP13-15, UFUJP13-16, UFUJP13-17 e UFUJP13-18) e duas cultivares (Delta Opal e FM 966).

O delineamento experimental utilizado foi o de blocos completos casualizados (DBC) com três repetições. A parcela experimental constituiu-se de quatro linhas de cinco metros espaçadas de um metro. Considerou-se como parcela útil as duas linhas centrais.

Foram semeadas 16 sementes por metro linear a dois centímetros de profundidade. O desbaste ocorreu 20 dias após a emergência, deixando-se oito plantas por metro linear, para obtenção de uma população de 80.000 plantas ha-1 (EMBRAPA, 2003).

Realizou-se a colheita manual dos capulhos, planta por planta, por meio da amostragem de 30 capulhos do terço médio das plantas da parcela útil. Realizou-se o descaroçamento das amostras no Laboratório de pesquisa do algodoeiro localizado na Fazenda Capim Branco e separado uma amostra de pluma de $50 \mathrm{~g}$ para análise. As amostras foram analisadas quanto a qualidade da fibra no Laboratório de análise de fibras da Associação Mineira de Produtores de Algodão, Minas Cotton, localizado em Uberlândia - MG.

Com o auxílio do instrumento HVI avaliou-se as características: índice de consistência a fiação (ICF), índice micronaire (IM), maturidade da fibra (MF), comprimento da fibra (CF), uniformidade de comprimento (UC), índice de fibras curtas (IFC), resistência (RS), alongamento (AL), reflectância $(\mathrm{RF})$ e grau de amarelecimento (GA). 
Os dados foram submetidos aos testes de normalidade (Kolmogorov-Smirnov) e homogeneidade (Levene), ambos a 0,05 de significância. Posteriormente realizou-se à análise de variância (Teste F) e o teste de Scott Knott, ambos também a 0,05 de significância. Determinou-se o coeficiente de determinação genotípico $\left(\mathrm{h}^{2}\right)$.

As análises estatísticas foram realizadas com o auxílio do Programa Genes (Cruz et al., 2013) e SPSS $®$.

\section{RESULTADOS E DISCUSSÃO}

Os 22 genótipos do algodoeiro do PROMALG apresentaram variabilidade genética para todos os caracteres que determinam a qualidade da fibra, com exceção da maturidade, em que todos os genótipos ficaram no mesmo grupo, e essa variação foi em maior parte de natureza genética (Tabela 1).

O coeficiente de variação (CV) para os caracteres analisados oscilou de $1,09 \%$ para UC à $10,22 \%$ para IFC, valores aceitáveis por se tratar de características quantitativas, governada por muitos genes, e consequentemente muito influenciadas pelo ambiente.
Jeronimo (2014) ao avaliar genótipos de algodoeiro quanto a qualidade da fibra obteve $\mathrm{CV}$ de $29,52 \%$ para IFC, $1,35 \%$ para UF e $29,52 \%$ AL, valores acima dos obtidos nesse trabalho, que segundo Garcia (1989) são considerados de baixo (inferiores a 10\%) à médio (entre 10-20\%).

Os valores para os coeficientes de determinação genotípica $\left(\mathrm{h}^{2}\right)$ demonstraram que a variação na qualidade da fibra é em maior parte de causa genética, o que permite a seleção mais efetiva dos genótipos superiores, com a garantia de que expressão a superioridade identificada no ciclo de seleção realizado. Os valores de $\mathrm{h}^{2}$ oscilaram entre 37,99\% à 99,53\%, para MF e GA, respectivamente. Valores de $\mathrm{h}^{2}$ acima de $70 \%$ são considerados altos, mas esse valor varia de acordo com a espécie e característica.

Altos $\mathrm{h}^{2}$ também foram obtidos para ICF $(93,46 \%)$, CF $(92,90 \%)$, UC $(83,43 \%)$, IFC $(95,56 \%)$, R $(88,51 \%)$ e RE $(98,65 \%)$, todos com valores acima de $70 \%$.

A MF sofreu forte influência ambiental, com $\mathrm{h}^{2}$ de $37,99 \%$, a variação entre os genótipos é o que demonstra que $62,01 \%$ da variação na MF é de causa ambiental (SANTOS \& GHEYI, 2003).

Tabela 1-Média das características intrínsecas da fibra de 22 genótipos de algodoeiro, Uberlândia-MG, $2012 / 2013$.

\begin{tabular}{|c|c|c|c|c|c|c|c|c|c|c|}
\hline GENÓTIPO & ICF & IM & $\begin{array}{l}\text { MF } \\
(\%)\end{array}$ & $\begin{array}{c}\mathbf{C F} \\
(\mathbf{m m})\end{array}$ & $\begin{array}{l}\mathrm{UC} \\
(\%)\end{array}$ & $\begin{array}{l}\text { IFC } \\
(\%) \\
\end{array}$ & $\begin{array}{c}\mathbf{R} \\
\text { (gf/tex) }\end{array}$ & $\begin{array}{c}\mathbf{A L} \\
(\mathbf{m m})\end{array}$ & $\begin{array}{l}\mathrm{RE} \\
(\%)\end{array}$ & GA \\
\hline UFUJP13-1 & 141,66 a & $4,09 \mathrm{a}$ & $0,83 \mathrm{a}$ & $29,42 \mathrm{a}$ & 84,26 a & $7,63 \mathrm{c}$ & $28,90 \mathrm{a}$ & $8,75 \mathrm{a}$ & $75,76 \mathrm{a}$ & $8,83 \mathrm{~b}$ \\
\hline UFUJP13-2 & 137,66 a & $4,04 \mathrm{a}$ & $0,84 \mathrm{a}$ & $28,88 \mathrm{a}$ & 83,26 a & $7,36 \mathrm{c}$ & $29,60 \mathrm{a}$ & $8.46 \mathrm{a}$ & $77,73 \mathrm{a}$ & $9,10 \mathrm{~b}$ \\
\hline UFUJP13-3 & $140,33 \mathrm{a}$ & $3,75 \mathrm{~b}$ & $0,83 \mathrm{a}$ & $29,71 \mathrm{a}$ & $83,03 \mathrm{a}$ & $8,03 \mathrm{c}$ & $28,86 \mathrm{a}$ & $8,30 \mathrm{a}$ & 80,06 a & $8,70 \mathrm{~b}$ \\
\hline UFUJP13-4 & 138,33 a & $3,81 \mathrm{a}$ & $0,83 \mathrm{a}$ & $29,03 \mathrm{a}$ & 82,93 a & $7,83 \mathrm{c}$ & 29,43 a & $8.16 \mathrm{~b}$ & $78,33 \mathrm{a}$ & $8.53 \mathrm{~b}$ \\
\hline UFUJP13-5 & $141,00 \mathrm{a}$ & $3,61 \mathrm{~b}$ & $0,83 \mathrm{a}$ & $29,25 \mathrm{a}$ & $82,83 \mathrm{a}$ & $7,73 \mathrm{c}$ & 29,90 a & $8.36 \mathrm{a}$ & $79,90 \mathrm{a}$ & $8,66 \mathrm{~b}$ \\
\hline UFUJP13-6 & 143,66 a & $3,96 \mathrm{a}$ & $0,84 \mathrm{a}$ & $30,26 \mathrm{a}$ & $83,90 \mathrm{a}$ & $7,13 \mathrm{c}$ & $29,40 \mathrm{a}$ & $7.46 \mathrm{~b}$ & $79.50 \mathrm{a}$ & $8,93 \mathrm{~b}$ \\
\hline UFUJP13-7 & $150,00 \mathrm{a}$ & $4,01 \mathrm{a}$ & $0,84 \mathrm{a}$ & $30,09 \mathrm{a}$ & $84,10 \mathrm{a}$ & $7,30 \mathrm{c}$ & $31,03 \mathrm{a}$ & $7,96 \mathrm{~b}$ & 80,36 a & $8,00 \mathrm{~b}$ \\
\hline UFUJP13-8 & $145,00 \mathrm{a}$ & $4,02 \mathrm{a}$ & $0,84 \mathrm{a}$ & $29,91 \mathrm{a}$ & $83,80 \mathrm{a}$ & $7,30 \mathrm{c}$ & $30,33 \mathrm{a}$ & $8,03 \mathrm{~b}$ & $78,63 \mathrm{a}$ & $8,36 \mathrm{~b}$ \\
\hline UFUJP13-9 & 139,33 a & $4,02 \mathrm{a}$ & $0,84 \mathrm{a}$ & $29,93 \mathrm{a}$ & 83,26 a & $7,50 \mathrm{c}$ & 29,16 a & $7,90 \mathrm{~b}$ & $78,66 \mathrm{a}$ & $8.63 \mathrm{~b}$ \\
\hline UFUJP13-10 & $128,00 \mathrm{a}$ & $3,93 \mathrm{a}$ & $0,84 \mathrm{a}$ & $28,76 \mathrm{a}$ & 82,33 a & $8.40 \mathrm{c}$ & 27,33 a & $7,60 \mathrm{~b}$ & $78,56 \mathrm{a}$ & $8,46 \mathrm{~b}$ \\
\hline UFUJP13-11 & $144,00 \mathrm{a}$ & $4,18 \mathrm{a}$ & $0,84 \mathrm{a}$ & $30,02 \mathrm{a}$ & $84,00 \mathrm{a}$ & $6.96 \mathrm{c}$ & $29,53 \mathrm{a}$ & $8,16 \mathrm{~b}$ & $78,63 \mathrm{a}$ & $8,46 \mathrm{~b}$ \\
\hline UFUJP13-12 & $151,00 \mathrm{a}$ & $4,26 \mathrm{a}$ & $0,85 \mathrm{a}$ & 29,69 a & 84,86 a & $6.73 c$ & $31,40 \mathrm{a}$ & $7,80 \mathrm{~b}$ & $79,60 \mathrm{a}$ & $8,73 \mathrm{~b}$ \\
\hline UFUJP13-13 & 142,66 a & $3,90 \mathrm{a}$ & $0,84 \mathrm{a}$ & $29,41 \mathrm{a}$ & 83,66 a & $7,56 \mathrm{c}$ & 29,70 a & $7,73 \mathrm{~b}$ & $78,36 \mathrm{a}$ & $8,40 \mathrm{~b}$ \\
\hline UFUJP13-14 & 144,66 a & $4,01 \mathrm{a}$ & $0,84 \mathrm{a}$ & $30,42 \mathrm{a}$ & 83,60 a & $6,96 \mathrm{c}$ & 30,26 a & $7,76 \mathrm{~b}$ & $77,76 \mathrm{a}$ & $8,70 \mathrm{~b}$ \\
\hline UFUJP13-15 & 145,33 a & $3,92 \mathrm{a}$ & $0,83 \mathrm{a}$ & $30,40 \mathrm{a}$ & 83,63 a & $6,90 \mathrm{c}$ & 30,33 a & 8,70 a & $77.56 \mathrm{a}$ & $8,60 \mathrm{~b}$ \\
\hline UFUJP13-16 & $142,33 \mathrm{a}$ & $3,96 \mathrm{a}$ & $0,84 \mathrm{a}$ & $30,20 \mathrm{a}$ & 82,83 a & $7,26 \mathrm{c}$ & 30,46 a & $8,43 \mathrm{a}$ & 78,66 a & $8,70 \mathrm{~b}$ \\
\hline UFUJP13-17 & $58,33 \mathrm{c}$ & $3,52 \mathrm{~b}$ & $0,82 \mathrm{a}$ & $21,18 \mathrm{~b}$ & $78,70 \mathrm{c}$ & $17,33 \mathrm{a}$ & $18,96 \mathrm{c}$ & $9,26 \mathrm{a}$ & $46,20 \mathrm{~b}$ & $18,63 \mathrm{a}$ \\
\hline UFUJP13-18 & 147,66 a & $3,94 \mathrm{a}$ & $0,84 \mathrm{a}$ & $29,78 \mathrm{a}$ & $84,26 \mathrm{a}$ & $7,23 \mathrm{c}$ & 30,33 a & $8,00 \mathrm{~b}$ & $78,30 \mathrm{a}$ & $8,93 \mathrm{~b}$ \\
\hline UFUJP13-19 & $143,33 \mathrm{a}$ & $3.89 \mathrm{a}$ & $0,84 \mathrm{a}$ & $29,65 \mathrm{a}$ & $83,30 \mathrm{a}$ & $7,46 \mathrm{c}$ & 30,33 a & 8,40 a & $78,46 \mathrm{a}$ & $8,53 \mathrm{~b}$ \\
\hline UFUJP13-20 & $100,00 \mathrm{~b}$ & $3,31 \mathrm{~b}$ & $0,82 \mathrm{a}$ & $27,11 \mathrm{a}$ & $81,03 b$ & $11,13 \mathrm{~b}$ & $24,96 \mathrm{~b}$ & $8,30 \mathrm{a}$ & $46,00 \mathrm{~b}$ & $18,70 \mathrm{a}$ \\
\hline Delta Opal & $137,00 \mathrm{a}$ & $3,94 \mathrm{a}$ & $0,84 \mathrm{a}$ & 29,37 a & 82,56 a & $7,93 \mathrm{c}$ & 29,63 a & $8,03 \mathrm{~b}$ & $78,26 \mathrm{a}$ & $9.10 \mathrm{~b}$ \\
\hline FM 966 & 142,66 a & $3.98 \mathrm{a}$ & $0,84 \mathrm{a}$ & $29,60 \mathrm{a}$ & 83,53 a & $7,30 \mathrm{c}$ & 29,86 a & $8,23 \mathrm{a}$ & $78,96 \mathrm{a}$ & $8.83 \mathrm{~b}$ \\
\hline$h^{2}(\%)$ & $93,46 \%$ & $60,75 \%$ & $37,99 \%$ & $92,90 \%$ & 83,43 & $95,56 \%$ & $88,51 \%$ & $65,82 \%$ & $98,65 \%$ & $99,53 \%$ \\
\hline $\mathrm{KS}$ & 0,10 & 0,11 & 0,14 & $\mathbf{0 , 0 7}$ & 0,07 & 0,06 & 0,11 & 0.06 & 0,15 & 0,06 \\
\hline$F_{\text {Levene }}$ & 3,09 & 4,12 & 1,72 & 1,66 & 2,37 & 4.30 & 3.20 & 2,39 & 5.92 & 1.59 \\
\hline $\mathrm{CV}$ & 6,56 & 5,88 & 1.24 & 3.04 & 1.09 & 10.23 & 5.28 & 5.13 & 2.56 & 3.63 \\
\hline TRANS & - & - & $\sqrt{x+0,5}$ & $\sqrt{x}$ & $\sqrt{x}$ & - & - & $\sqrt{x}$ & - & $\sqrt{x}$ \\
\hline
\end{tabular}

${ }^{1}$ Médias seguidas de letras iguais pertencem ao mesmo grupo pelo teste de Scott-Knott a 0,05 de significância. ICF = Índice de consistência a fiação; IM = Micronaire (adimensional), MF= Maturidade da fibra, $\mathrm{CF}=$ Comprimento da fibra $(\mathrm{CF}), \mathrm{UC}=$ Uniformidade de comprimento $(\%)$, IFC= Índice de fibras curtas $(\%), \mathrm{R}=$ Resistência ( $\mathrm{gf} / \mathrm{tex}), \mathrm{AL}=$ Alongamento $(\mathrm{mm}), \mathrm{RE}=$ Reflectância $(\mathrm{RE})$ e G.A= Grau de amarelecimento.h ${ }^{2}=$ coeficiente de determinação genotípico. KS e F: estatísticas dos testes Kolmogorov- Smirnov e Levene, valores em negrito indicam resíduos com distribuição normal e variância homogênea, respectivamente. TRANS: transformação realizada. 
Para ICF, UC e IFC os genótipos se dividiram em três grupos, e para IM, CF, R, AL, RE e GA em dois grupos, o que demonstra a existência de variabilidade genética entre os genótipos avaliados e potencial de seleção (Tabela 1).

Além da expressão do potencial genético dos genótipos, as características que determinam a qualidade da fibra devem atender a valores mínimos, para que a indústria aceite a pluma no processo de produção, e para o desenvolvimento de genótipos com características intrínsecas da fibra superiores é primordial que haja variabilidade genética na população de trabalho, para que se realize a seleção dos melhores genótipos, para seguir no processo de melhoramento.

O ICF que julga e balanceia as características mais importantes de qualidade da fibra, deve ser superior a 140 (SESTREM; LIMA, 2007). Todos os genótipos apresentaram valores de ICF acima do exigido pela indústria têxtil, com exceção das linhagens UFUJP13-17 (58,33) e UFUJP13-20 $(100,00)$. Silva $(2014)$ ao avaliar a qualidade de genótipos de algodão, obteve resultados semelhantes, com valores entre 122,3 e136,3.

O IM é um dos mais importantes na determinação da qualidade e do preço pago pelo algodão produzido. $\mathrm{O}$ ideal para a indústria é que o mesmo esteja com valores entre 3,5 a 4,2 (EMBRAPA, 2002). Todos os genótipos ficaram dentro deste padrão, exceto a linhagem UFUJP13-20 (3,31). Echer (2014) em seu trabalho verificou que valores de IM abaixo de 3,5 indicam algum grau de imaturidade da fibra, e difícil de ser trabalhada no processo de fiação.

Sendo a MF de grande importância na qualidade da fibra, os genótipos avaliados apresentam valores dentro do padrão estabelecido, que está acima de $80 \%$. A MF média obtida foi de $83 \%$, apensar de os genótipos não terem apresentados variabilidade para essa característica, a linhagem UFUJP13-12 apresentou a maior média (85\%) e mesmo com valores que atendem exigências da indústria têxtil, esses ficaram abaixo dos encontrados por Araújo (2013), que obteve média de $90 \%$.

O valor de CF exigido é de no mínimo $27 \mathrm{~mm}$, no qual apenas a linhagem UFUJP13-17 não atendeu, apresentando CF de 21,18 mm, o que pode ter ocorrido devido ao estresse hídrico que as plantas dos genótipos sofreram na fase de crescimento vegetativo e início da floração, o que acabou refletindo na formação da fibra, uma vez que a mesma se inicia logo após a antese.

Cada genótipo nesse caso respondeu de forma diferenciada ao estresse sofrido. A média obtida de CF foi de 29,07 mm, que de acordo com Santana \& Wanderley (1995), são consideradas fibras longas, valor este, muito satisfatório e semelhante ao obtido por Araújo et al. (2013) (30 mm).

Ao analisar a UC, com exceção da linhagem UFUJP13$17(78,70 \%)$, que não atingiu o valor recomendado pela indústria (acima de 80\%), todas os genótipos foram superiores, com média acima do exigido. A maturação precoce do algodão prejudica a formação das maçãs do ponteiro, que reflete na uniformidade da fibra produzida e o déficit hídrico e um dos fatores ambientais que mais tem influência na qualidade da fibra.

A linhagem UFUJP13-20 foi a que apresentou menor média de UC (81,03\%). Araújo et al. (2013) ao avaliarem a fenologia, características agronômicas e tecnológicas da fibra de cultivares de algodoeiro herbáceo, a fim de identificar e selecionar cultivares mais promissoras para o plantio no semiárido nordestino obtiveram UC média de 85,67 \%, acima da média obtida nesse trabalho $(83,17 \%)$. A UC é uma característica influenciada pelo genótipo e ambiente. Karademir et al. (2012) ao avaliar a qualidade de genótipos de algodão obtiveram média de UC de 85,13\%, com máxima de $85,77 \%$, valor superior ao obtido nesse trabalho que foi de $84,86 \%$ para a linhagem UFUJP13-12.

Para índice de fibras curtas (IFC) são aceitos valores menores que $10 \%$, o que desclassifica as linhagens UFUJP1317 e UFUJP13-20 para a indústria têxtil, pois obtiveram valores de $17,33 \%$ e $11,13 \%$, respectivamente. Valores acima de $10 \%$ acarreta em dificuldades no processo de fiação, por produzir fios de baixa qualidade e com "neps". Grande percentagem de fibras curtas ocasiona fios com grossuras irregulares, podendo romper-se nos locais mais finos e fracos, durante a fiação e tecelagem (EMBRAPA, 2002).

Uma característica que apresenta correlação com fibras curtas é a maturidade da fibra. Logo, quanto menor a maturidade, maior será o índice de fibras curtas. Na média geral, os genótipos apresentaram bom resultado, com valores abaixo de $10 \%$, sendo bem aceito pela indústria, mas ficou abaixo do obtido por Silva et al. (2013), que obteve média de $4,84 \%$, ao avaliar a qualidade da fibra de genótipos nas condições da Paraíba.

A resistência é outra característica importante na determinação da qualidade e fiação da pluma produzida. No desenvolvimento de novas cultivares, os melhoristas priorizam a seleção de genótipos com $\mathrm{R}$ acima de 28 gf.tex $^{-1}$ (MAPA, 2002). As linhagens UFUJP13-17 e UFUJP13-20 foram as únicas que apresentam valores médios abaixo do recomendado pela indústria têxtil e priorizado pelos melhoristas, 18,96 gf.tex ${ }^{-1}$ e 24,96 gf.tex ${ }^{-1}$, respectivamente. Fatores ambientais influenciam significativamente na resistência da fibra e o déficit hídrico também afeta na $\mathrm{R}$ a pluma produzida pelos genótipos, uma vez que na fase de formação do capulho (90-140 dias após germinação) (DOORENBOS; KASSAN, 2000) o algodoeiro necessita de aproximadamente $291 \mathrm{~mm}$, o que não ocorreu durante a condução do experimento.

Umidade excessiva na colheita e fatores genéticos também interferem na resistência da fibra. A média dos genótipos apresentaram um resultado acima do exigido $(29,07$ gf.tex $^{-1}$ ), mas abaixo do obtido por Silva et al. (2013) onde a menor resistência da fibra foi de 31,31 gf.tex ${ }^{-1}$. Karademir et al. (2012) obteve média de 31,50 gf.tex ${ }^{-1}$.

$\mathrm{O}$ alongamento da fibra tem como valor ideal de no mínimo 7mm (EMBRAPA, 2002), no estudo todos os genótipos apresentaram valores acima. De acordo com Lima; Nabas (1995) e Santana; Wanderley (1995), as fibras analisadas foram classificadas, segundo o alongamento, na categoria de muito alta, acima de 7,6\%. Araújo et al. (2013), encontraram média, para esta característica de 4,10mm. Karademir et al. (2012), obteve uma média de $6,07 \mathrm{~mm}$, ambos abaixo da média obtida nesse trabalho, que foi de $8,18 \mathrm{~mm}$.

A reflectância ideal é de 70\% (SESTREM; LIMA, 2007) e como as características que determinam a qualidade da fibra são correlacionadas, as linhagens UFUJP13-17 e UFUJP1320, que apresentam resultados ruins para MF, IFC e $R$, também não atenderam a exigência da indústria textil para $R$. O tempo de armazenamento diminui a reflectância da fibra (LIMA,2009), mas cada genótipo responde de forma 
diferenciada. Antes do envio das amostras para análise, as mesmas ficaram armazenadas no laboratório, o que pode ter influenciado na $\mathrm{R}$ dos genótipos.

Santana et al. (2002) afirmaram que a cor da fibra do algodão varia por influência de fatores intrínsecos, relativos a cultivar e extrínsecos, com as condições de armazenamento. Os outros genótipos obtiveram valores acima do aceitável para este quesito. Araújo et al. (2013), no experimento de características fenotípicas obtiveram média de 74,05\%. Karademir et al. (2012), encontraram média de 76,03\% para esta característica, estando acima dos valores exigidos pela indústria.

Para grau de amarelecimento valores ideais devem estar entre 4 e 18 (SANTANA; WANDERLEY, 1995; SANTANA, 2002). Todos os genótipos ficaram dentro deste valor, exceto as linhagens UFUJP13-17 e UFUJP13-20, que obtiveram valores acima do máximo exigido $(18,00), 18,63$ e 18,70 , respectivamente. Santana et al. (2002) afirmaram que a cor da fibra do algodão variar por influência de fatores intrínsecos, relativos a cultivar e extrínsecos, com as condições de armazenamento. Bernades (2012) encontrou 7,83 no amarelecimento da fibra de genótipos de algodoeiro nas condições de Uberaba-MG. Silva et al. (2013), encontraram valores entre 8,74 a 10,09, estando dentro dos valores aceitáveis pela indústria têxtil.

\section{CONCLUSÕES}

1 As linhagens do Programa de Melhoramento genético do Algodoeiro da Universidade Federal de Uberlândia, com exceção da UFUJP13-17 e UFUJP13-20, atendem as exigências da indústria têxtil e apresentam variabilidade suficiente para seguir no processo de melhoramento.

2 A variação entre os genótipos foi em maior parte de natureza genética, com coeficiente de determinação acima de $80 \%$.

\section{AGRADECIMENTOS}

Os autores agradecem a Associação Mineira de Produtores de Algodão (AMIPA) e ao Laboratório de análises de fibra da Minas Cotton, pelo auxílio nas avaliações, e a Fundação de Apoio à Pesquisa do Estado de Minas Gerais (FAPEMIG), pelo apoio financeiro.

\section{REFERÊNCIAS BIBLIOGRÁFICAS}

ABRAPA. Associação Brasileira dos Produtores de Algodão. O algodão no mundo. Disponível em: http://www.abrapa.com.br/estatisticas/Paginas/Algodaono-Mundo.aspx. Acesso em: 20 out. 2014.

ARAÚJO et al. Características fenológicas, agronômicas e tecnológicas da fibra em diferentes cultivares de algodoeiro herbáceo. Rev. Bras. Ciênc. Agrár. Recife, v.8, n.3, p.448-453, 2013.

BELTRÃO, N. E. de M.; ARAÚJO, A. E. de. (Ed.). Algodão: o produtor pergunta, a Embrapa responde. Brasília, DF: Embrapa Informação Tecnológica; Campina Grande: Embrapa Algodão, 2004. 265 p. il. (Coleção 500 perguntas, 500 respostas).
BEZERRA J. R. C.; AZEVEDO P. V; SILVAB.B.; DIAS, J. M. Evapotranspiração e coeficiente de cultivo do algodoeiro BRS-200 Marrom, irrigado. Rev. bras. eng. agríc. ambient, vol.14, no.6, Campina Grande, 2010.

CHITARRA, L.G. Identificação e controle das principais doenças do algodoeiro. Luiz Gonzaga ChitarrA - 3. ed. - Campina Grande: Embrapa Algodão, 2014.

CONAB Companhia Nacional de Abastecimento - Algodão disponível em:http://www.agricultura.gov.br/arq_editor/file/camara s_setoriais/Algodao. Acesso: set. 2015.

CRUZ, C.D. Programa GENES: biometria. Viçosa: UFV, 2006. 382p.

DOORENBOS J.; KASSAN.H, Efeito da água no rendimento das culturas. Campina Grande/PB: UFCG,2000 306p.

ECHER F. R. O algodoeiro e os estresses abióticos: temperatura, luz, água e nutrientes. Instituto MatoGrossense do Algodão - IMAmt - Cuiabá (MT), 2014 (IMAMT. Boletim de P\&D, 1), p. 123.

EMBRAPA Resultados de Ensaio HVI e Suas Interpretações (ASTM D-4605). ISSN 0100-6460. Circular Técnica. 66. Campina Grande, PB. Dezembro, 2002.

EMBRAPA. Algodão sistemas de produção: Cultura do Algodão no Cerrado.ISSN:1678-8710 Versão Eletrônica http://sistemasdeproducao.cnptia.embrapa.br/FontesHT ML/Algodao/AlgodaoCerrado/plantasdaninhas.htm>: Jan/2003 Acesso em: out. 2014.

FREIRE, E.C et al. Cultura do algodoeiro no Estado de Mato Grosso. Campina Grande: Embrapa Algodão, 1997. 65p. (Embrapa Algodão. Circular Técnica, 23).

ICAC - Cotton this month - international cotton advisory committee. Disponível em: <http://www.icac.org. Acesso em: 31 de maio de 2015.

LIMA, L. A. Efeitos de sais no solo e na planta. In: Gheyi, H. R.; Campina Grande UFPB; SBEA, 1997. p.113-136.

JERÔNIMO J. F. et al. Qualidade da semente e fibra de algodão na caracterização do descaroçador de $\mathbf{2 5}$ serras. R. Bras. Eng. Agríc. Ambiental, v.18, n.6, p.664$671,2014$.

KARADEMIR, E.; KARADEMIR, C.; BASBAG, S. Effect of Verticillium dahlia Kleb. On cotton yield and fiber technological properties. International Journal of Plant Production, n.6, v.4, p. 387-408, 2012.

LIMA A. K. V. O. Caracterização da reflectância e grau de amarelamento da fibra do algodão BRS200 Marrom armazenada. Revista de biologia e ciências da 
terra ISSN 1519-5228 Volume 9 - Número 2 - $2^{\text {o }}$ Semestre 2009.

LIMA, A.P.; NABAS, H.T. Relatório do laboratório tecnológico de fibras da BM \& F. São Paulo: BM \& F, 1995 , p. 43.

MAPA - Ministério de Agricultura, Pecuária e Abastecimento, IN - Instrução Normativa $\mathbf{N}^{\mathbf{0}}$ 63. 05 de dezembro de 2002.

PEDROSA M. B. Evolução da cadeia para construção de um setor. Anais. Campina Grande, PB: Embrapa Algodão, 2011. p.1234-1241.

PENNA, J.C.V. Melhoramento do algodoeiro. In: BORÉM, A. Melhoramento de espécies cultivadas. Viçosa: UFV,2005. p 15-53.

PENNA, J. C. V. Melhoramento do Algodoeiro Anual. Informe 21 Agropecuário, Belo Horizonte, v.8, n.92, p.10-13, 1982.

RESENDE M.A.V. Divergência genética e índice de seleção via BLUP em acessos de algodoeiro para características tecnológicas da fibra. Pesq. Agropec. Trop., Goiânia, v. 44, n. 3, p. 334-340, 2014.

SANTANA, J.C.F. DE; WANDERLEY, M.J.R. Interpretação de resultados de análises de fibras efetuadas pelo instrumento de alto volume (HVI) e pelo finurímetro-maturímetro. (FMT2). Campina Grande: EMBRAPA-CNPA, 1995. 9p. Comunicado Técnico 41.

SANTANA, J.C. DA S. Características tecnológicas da fibra de duas cultivares de algodão armazenadas em dois municípios paraibanos. Campina Grande: UFCG, 2002. 48p. Dissertação Mestrado.

SANTOS, J. W.; GHEYI, H. R. Estatística Experimental Aplicada. Campina Grande: Ed. Gráfica Marcone Ltda., 2003. $213 \mathrm{p}$.

SESTREN, J. A.; LIMA, J. J. Característica e classificação da fibra de algodão. In: FREIRE, E.C. (Ed.). Algodão no cerrado do Brasil. Brasília: ABRAPA, 2007. p.765820.

SILVA, G.; OLIVEIRA, R. A.; QUEIROZ, N. L. Q.; MELCHIOR N. B. SILVA, M. F. S. S. Desempenho agronômico de algodão orgânico e oleaginosas consorciados com palma forrageira. Engenharia agrícola e ambiental, v.17, p.975-981, 2013.

VIDAL NETO, F. das C.; FREIRE, E. C. Melhoramento do algodoeiro. In: Simpósio nordestino de genética e melhoramento de plantas, 1, 2009, Fortaleza. Anais. Fortaleza: Embrapa Agroindústria Tropical, 2009. p. 102-120. 